\title{
Interaction researching mental spaces of movable context, stakeholders, and project manager
}

DOI 10.1515/otmcj-2016-0021

Received November 11, 2017; accepted November 13, 2017

Abstract: As practice shows, the success of project implementation depends on the clear and integrated interaction between stakeholders, the project manager, and the movable context. Such an interaction exists on the level of mental spaces. If the mental spaces are congruent, in other words, all things are in the space of clear and univocal understanding of all aspects of the project, "are speaking the same language," then project implementation is clear, exact, and in time.

On practice, it is observed that full understanding is absent during project initialization and implementation and mental space cannot be congruent completely or is congruent partially. This situation exists during the implementation of the international projects, which involves working together with specialists from different countries. In this case, the project manager must organize interaction between different mental spaces.

A research hypothesis consists of the assumption that the interaction between mental spaces of the movable context, stakeholders, and the project manager is carried out in a blended mental space. This space is temporary in relative to other mental spaces during the project life cycle; the project manager should manage this space through the usage of different skills.

The research was carried out by scientific methods of theories of mental and blended spaces, and the theory of knowledge, i.e. theoretical and empirical research using project management approaches.

The research's results showed that organization of interaction in the blended mental space with using appropriate competencies of the project manager provides successful project implementation. The theoretical base of research is presented in the example of the implementation of one

\footnotetext{
*Corresponding author: Olena Verenych, Project Management Department, \#31, Povitroflotskyi avenue, Kyiv, Ukraine, 03037, E-mail: verenych@ukr.net

Sergey Bushuyev, Project Management Department, \#31, Povitroflotskyi avenue, Kyiv, Ukraine, 03037,

E-mail: sbushuyev@turnkey
}

of the largest infrastructure projects in Ukraine: New Safe Confinement Construction.

Keywords: blended mental space, competences, movable context, stakeholder, project manager, interaction

\section{Introduction}

Construction is one of the areas of activities in which the project management methods and approaches have a positive outcome. An additional point is that standardization in the topical area makes easier the introduction of project management approaches in practice. This statement is correct when standard construction projects are implemented. Nevertheless, how can this approach function if there is a unique construction project that has not ever been implemented? Is it necessary then? What should be the focus?

Based on case studies in the implementation of construction projects, it can be argued that the usage of project management approaches is effective and useful. Nevertheless, an essential prerequisite will be an integrated understanding of both the project processes and the project product. An integrated understanding is formed in a blended mental space. This space exists during the project implementation. It originates at the intersection of other mental spaces: the project manager/project team, the movable context, and the stakeholders. How do these mental spaces interact with each other during the project implementation? What competence elements should a project manager have to create and support for the appropriate interaction between mental spaces during project implementation? How can such mental spaces be built that can help to implement the project?

According to Verenych (2015a), the overall mental space consists of four mental spaces: movable context, project manager, stakeholders, and project. Mental spaces of the movable context, the project manager, and stakeholders were researched separately in Verenych (2016a), Verenych (2015b), and Verenych (2016b), respectively.

Each of these spaces has its own characteristics, and the project manager should know and understand not only these 
features but also certain principles of interaction between these spaces and have the necessary competence elements to further manage them while introducing the project.

Interaction between mental spaces of the movable context, stakeholders, and the project manager and definition of those competence elements of the project manager that will be the driving forces for controlling the interaction between mental spaces can be considered as an advanced research.

The obtained theoretical results will be illustrated by the project "New Safe Confinement Construction" (hereinafter NSCC) at the Chernobyl Nuclear Power Plant (hereinafter CNPP) in Ukraine.

The author believes that the results published in this article will be interesting for both scientists involved in scientific research in the project management field and practitioners involved in the implementation of the project.

\section{Literature review}

The implementation of projects often faces problems of univocal understanding of initialization, planning, implementation, and closing of projects. The reasons for such misunderstanding may be a lack of interaction between the project manager and stakeholders and the movable context or lack of understanding and control of such interaction by the project manager. The project manager may have direct, mediated, or lack all interaction with stakeholders and the movable context. Interaction between the project manager, stakeholders, and the movable context takes place in a mental space where knowledge, skills, and practice are combined (Verenych 2015a, 2015b).

Moreover, the success of any project implementation depends on clear understanding of project's objectives and values, and univocal application of this understanding on a management level by the project manager, stakeholders, and the movable context. In other words, the understanding is on the level of integration of mental spaces (Salikov 2006). This integration creates a new blended mental space, which depends on the degree of similarity between constructed spatial configurations, ${ }^{1}$ and appears during initialization, planning, and/or implementation and exists until closing of the project.

Analysis of the literature showed that different approaches exist for the study of mental spaces of the movable context, stakeholders, and the project manager and their interactions. In most cases, these concepts are studied independent of each other.

1 http://studopedia.org/5-67534.html (accessed 11 November 2017).
Among a large number of mental space researches, more attention is attracted (Nonaka and Takeuchi 1995) where the authors discuss the mental space from the standpoint of creation, transmission, and functioning of knowledge. In this paper, the process of transforming knowledge (Socialization, Externalization, Combination, Internalization [SECI] model) is described. This process is put on the basis of a series of researches that are dealing with knowledge management, which are operational in mental space.

In the following papers discussed, a mental space is already considered in the context organization and interaction between stakeholders. In Kutsenko (2011), a role of mental space in the process of formation of sustainable competitiveness is described. The model transformation of knowledge, which can possibly accelerate the exchange of new knowledge and innovation, is presented. In Bushuev et al. (2011), an approach to manage software society and its mental space is presented. This approach is considered only for the development of innovation systems. The model of mental space formation on the basis of interaction optimization of stakeholders in the development of knowledge is presented in the paper.

The next papers are devoted to researching of mental space, its formation, and transformation through projects that have been implemented for specific subject areas. Dynamic of transformation in a cooperative network of interorganizational knowledge in existing spaces: (physical, virtual, and mental) is analyzed in Trincade and Ataide (2013). Research on the dynamic of mental space development and informational interaction that occurs over the formation of a new type of emergency response worker in the turbulent environment of IT technologies is presented in Burak and Rak (2014). Boychenko et al. (2008) considered purposeful forming of mental space of project team of the distributed educational project. This mental space conduces development of individual mental space and is determined by the following factors: an information interaction between individuals and group of persons acting among themselves and with information technology tools that are created during the project life cycle, a process of closeness and mutual enrichment of individual mentalities of project's participants and involving intelligence of Internet technologies' applications as a didactical tool of project monitoring.

The paper Turner and Fauconnier (1995) should be marked among researchers who are concerned with the studying of interaction between mental spaces. In the paper, the authors had introduced a concept of blending space, which is formed by the interaction between other spaces and thus has its own concept of existence, allowing it to develop and grow into new associations. 
In the same perspective, it should be noted as a paper ${ }^{2}$ in which a concept of "mental representation" is analyzed as an internal (mental) image or format encoding. In the paper, the mental representation is understood as result or content decoding in the frame of information approach.

Research project's movable context and its management are also devoted to a significant amount of papers. In particular, DeKarlo (2005) is concerned with the definition of two factors: communication in real time and building a flexible organization that affects the implementation of project's movable context management. However, these factors are considered only for extreme projects. The project manager must take into account organizational, cultural, and social environments of the project during project implementation. Especially, attention has been drawn regarding this in Reschke and Schelle (1990). These environments are seen only from the stakeholders' position. Three aspects are considered (Mazur et al. 2004) in practice for business planning of movable context management: political, namely, the attitude of federal and local authorities towards a project; territorial, which includes the study of competitive offers in the market for similar products; and environmental, which is associated with the need to ensure the environmental safety of a project. The impact of the movable context on the project is demonstrated in Ludwig (2009). An example of the existence of certain external factors, which sometimes cannot be removed from the process of project management but can significantly affect management's success, is described in the paper. More details, without regard to specific subject area, on the movable context are described in Balashov et al. (2013) where defined groups of factors that affect project are economic environment, factors of political character, sociodemographic factors, factors of a legal nature, the natural and climatic factors, and science and technology factors. However, an approach to the analysis of these factors, their influence, relationships and methods of ranking is absent.

Lately, researches and description on the practical implementation of projects, in which an approach concerning the description of the mental space of the movable context is presented, appeared. In this paper, an application of P2M knowledge system in project activities is demonstrated (Yaroshenko et al. 2012). More often than not the approach touches innovative projects.

\footnotetext{
2 http://epistemology_of_science.academic.ru/410/\%D0\%BC\%D0 \%B5\%D0\%BD\%D1\%82\%D0\%B0\%D0\%BB\%D1\%8C\%D0\%BD\%D 0\%B0\%D1\%8F_\%D1\%80\%D0\%B5\%D0\%BF\%D1\%80\%D0\%B5\% D0\%B7\%D0\%B5\%D0\%BD\%D1\%82\%D0\%B0\%D1\%86\%D0\%B8 $\% \mathrm{D} 1 \% 8 \mathrm{~F}$ (accessed 11 November 2017).
}

Based on the fact that a mental space is often seen as a space of knowledge, a descriptive knowledge service model for modern project environment is presented in Hoffman and Boyle (2015).

There are a lot of publications that are concerned with researching of stakeholders within the implementation of the project. We can indicate ${ }^{3}$ where approaches to identify project's stakeholders and converting of poorly/ (not) interested stakeholders into interested stakeholders of the project are presented. Internal and external stakeholders of the company and their impact on its activities are researched in https://www.boundless.com/ accounting/textbooks/boundless-accounting-textbook/ introduction-to-accounting-1/overview-of-key-elementsof-the-business-19/business-stakeholders- internal-andexternal-117-6595 (accessed 18 November 2016). The basic principles for determining and ranking stakeholders are described in https://www.mindtools.com/pages/article/ newPPM_07.htm (accessed 11 November 2017). Development and presentation of semantic models and taxonomies and stakeholders' involvement in public-private partnership during the implementation of infrastructure projects are presented in El-Gohary et al. (2006). The Stakeholder Circle tool is proposed in Bourne and Walker (2006) to measure and visualize the influence of stakeholders on project management.

Using memes in project management is devoted to Whitty (2005).

\section{Interaction between mental spaces of the movable context, the project manager and stakeholders: research part}

\subsection{Interaction between mental spaces of the movable context and project manager}

The mental space of the movable context is a complex, moving, and dynamic space that can be described using a concentric model that takes into account all chain of impacts from global context to internal environment of organization (Verenych 2016a). According to this concentric model, the mental space of the movable context includes four sets: global context, country context, economic sector and organizational context. Each of these

$3 \mathrm{http} / / /$ www.aup.ru/articles/investment/26.htm (accessed 11 November 2017). 
sets consists of seven subsets of influences: political, economic, legal, infrastructural, scientific and technical, social, and natural and environmental. However, the impletion by elements of these subsets depends on the set in which these subsets have been included (Verenych 2016a). The number of elements in each subset may be essentially different and depends on a specific project; thus, parts of the elements can be ignored or cannot be taken into account because they do not affect or have no significant effect on the project. The other elements should be ranked (Verenych 2016a), and important elements should be identified. Among these certain elements are those elements with which the project manager can communicate directly, but there are some elements with which such cooperation cannot take place.

Such interaction occurs on the level of exchange of memes between the project manager and relevant set of mental space of the movable context. In the paper's context, the term "meme" is a simple information unit, which in the space of knowledge will be presented in the form of ideas and characters ("pure knowledge" that is transmitted consciously or unconsciously) and in the space of skills as the actual practice (materialized) of knowledge representation based on behavioral, cultural, and mental approaches (Verenych 2015a, 2015b). These memes, more often than not, are clearly understood by all participants of project's implementation. Interaction takes place on a platform "Ba." The platform $\mathrm{Ba}$ is distributed movable content for the joint creation of value platform. In this case, the platform is the blending mental space. The space is temporary and exists during project life cycle. It allows to interact the movable context and project manager most efficiently, and it generates project's value and innovation.

The project manager can have some management problems with sets of global context and country context. Sometimes, such management can be impossible. In this case, the project manager can realize the interaction with the mental space of the movable context through other mental spaces, such as stakeholders. Note that the approach of the theory of mental spaces (Glebkin 2013) will be stored and the blended mental space will appear in coordination with mental spaces of stakeholders and the project manager.

According to the Individual Competence Baseline, ICB Version 4.0 (ICB4) standard for evaluation of the project manager's competencies in the project management, the competence elements from all fields will be needed. There are competence elements such as "risk and opportunity" and "stakeholders" from the field "practice"; "negotiation," "personal communication," "results orientation," and "leadership" from the field "people"; and "power and interest" and "culture and values" from the field "perspective” (IPMA 2015).

Schematically, the interaction of various kinds of mental spaces of the movable context and project manager is presented in Figure 1.

The project manager should do the following steps for the organization of interaction with the movable context:

Step 1. Identify those sets of mobile context that will have the biggest impact on the project.

Step 2. Among the sets defined in step 1, select those with which the project manager can have direct interaction. If these do not exist, go to step 3. Otherwise, go to steps 2.1-2.2.

Step 2.1. In the defined sets, determine the subsets with which interaction is possible.

Step 2.2. In certain subsets, identify those elements that will have a significant impact on the project. Select methods and create information units for direct influence.

Step 3. Create a list of the sets that are not defined in step 2 (the project manager can have mediated influence).

Step 3.1. In certain subsets, identify those elements that will have a significant impact on the project.

Step 3.2. From the list of stakeholders, identify those through whom the project manager can organize the mediated influence on the elements. Develop approaches and create information units for affecting influence through selected stakeholders.

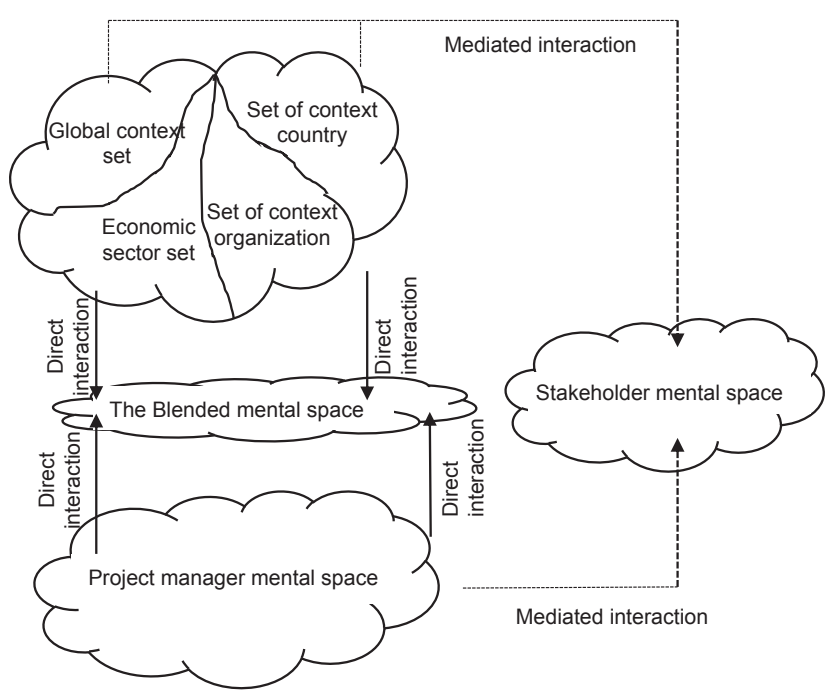

Fig. 1: Interaction between the mental spaces of the movable context and project manager. 


\subsection{Interaction of mental spaces of the project manager and stakeholders}

The project manager can interact with the mental space of stakeholders through the blended mental space during interaction between mental spaces of stakeholders and the project manager (Bushuev et al. 2011). Most often than not, this interaction is realized through impacts of stakeholders on the project. A corresponding mental space is creating via creating (new, combining existing) and spreading memes about the project. Using the space, you can change the number of stakeholders (to increase or decrease) and their impact on the project.

If the project manager needs to change the impact of stakeholders on the project or needs to expand the range of stakeholders, he/she should create relevant memes and bring them into the blended mental space. These memes must bear information that should be clear and correspond to knowledge, status, and cultural level of stakeholders. This is why the mental representation of meme should correspond to the stakeholders' mental space. These memes should expand the mental space and make provision for the entrance to the blended mental space through coming closer together of knowledge, culture, and interest of stakeholders to the mental space of the project manager.

The project manager/team project provides a migration of values from one mental space to another. However, such migration is possible only when memes from the stakeholders' mental space and the project manager's mental space intercross and combine in the blended mental space (Turner and Fauconnier 1995) (Figure 2). The management of the stakeholders' mental space from the side of the project manager takes place in it too. Such management can be realized through various forms of business communication, for example, meetings, panel sessions, gathering, and negotiations.

For the organization of this interaction, the project manager should use the next competence elements "stakeholders" and "organization and information" from the field "practice" and "personal communication," "leadership," and "negotiation" from the field "People" (IPMA 2015). where are:

The project manager should do the following steps for the organization of interaction with stakeholders:

Step 1. Create a list of all stakeholders.

Step 2. Identify what kind of influence stakeholders can have on the project manager (direct or mediated).

Step 3. If there is the mediated influence, identify the channels through which the project manager can influence directly and establish these channels for interaction.

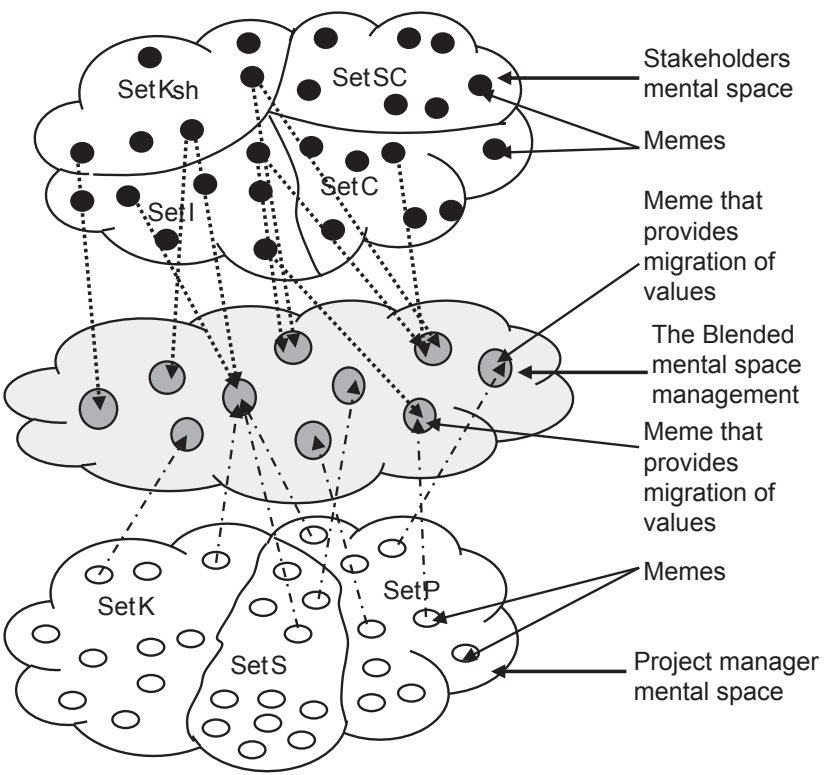

Fig. 2: Interaction between the mental spaces of stakeholders and the project manager.

$\mathrm{K}$ - set of project manager's knowledge; $\mathrm{S}$ - set of project manager's skills; P - set of project manager's practices; I - set of stakeholders' interests; $C$ - set of stakeholders' culture level; $\mathrm{K}_{\text {sh }}$ - set of stakeholders' knowledge; SC - set of stakeholders' status positions (Verenych 2016b).

Step 4. Determine the stakeholders' influence: positive, negative, or neutral.

Step 4.1. In case of positive influence, maintain and monitor the influence to prevent it from passing to neutral or negative influence.

Step 4.2. In the case of neutral influence, monitor the influence to back out changes to negative influence. Depending on the project support from the movable context and other stakeholders, the project manager can try to change the impact on the positive influence by preparing and disseminating appropriate information memes that will be understandable according to the knowledge, status position, and cultural level of the stakeholders.

Step 4.3. In case of negative influence,

Step 4.3.1. identify the transmission channels of information memes, which are best perceived by stakeholders; 
Step 4.3.2. prepare and disseminate information memes in which to provide information showing the positive impact of the project for the stakeholders;

Step 4.3.3. get feedback on the results of the dissemination of information memes. Feedback can be obtained as a response to the information provided in the form of influence change, survey results, and/or sociological researchers; and

Step 4.4.4. based on the results of feedback, steps 4.3.14.3.3, step 4.1, or step 4.2 should be repeated.

\subsection{Interaction between mental spaces of stakeholders, the movable context, and the project manager}

The project manager should understand the relationship between various mental spaces during project implementation. This relationship is organized through the blended mental space. The blended mental space, as mentioned previously, appears due to using of different competencies by which relevant memes are created for the management of the corresponding impact or changing negative influence to positive for the successful implementation of the project. This interaction is represented schematically in Figure 3 (note that any interaction - direct or indirect - exists through the blended mental space). It is strategically necessary for:

identification of most turbulent areas of project environment;

predicting the risk area; and

creating appropriate preventive measures and reducing the possibility of closing the project or in advance to save or to lay extra time and money to eliminate the consequences of risky events.

For organization of this interaction, the project manager should use all competence elements from the field "perspective"; "personal communication," "leadership," "conflict and crisis," "results orientation," and "negotiation" from the field "people"; and "stakeholders" and "organization and information" from the field "practice” (IPMA 2015).

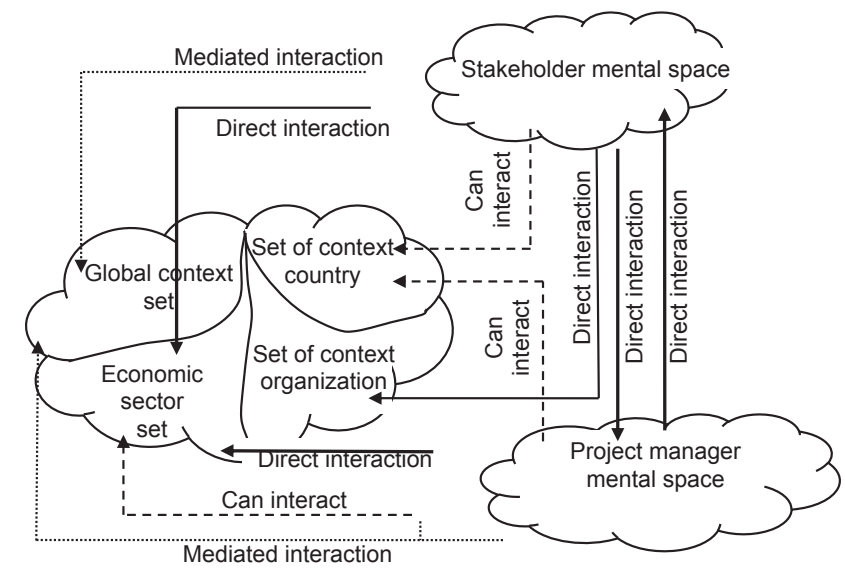

Fig. 3: Interaction between mental spaces of stakeholders, the project manager, and the movable context.

\section{Interaction between mental spaces of the movable context, the project manager and stakeholders: case study}

As exemplified by the project NSCC, we will consider the interaction between mental spaces of the project manager, stakeholders, and the movable context. This project is part of the portfolio "Reconstruction of the Shelter Object" of the State Specialized Enterprise CNPP. This portfolio was implemented in Ukraine ${ }^{4}$ at the expense of the international community. Finances were entrusted to manage the European Bank for Reconstruction and Development (EBRD). The Shelter Object is the fourth unit of the CNPP. It is located in Ukraine. In this unit, a big man-made accident took place in 1986. As a result of the accident, the fourth unit was destroyed and a large number of jetting actions were released into the air. Ukraine and Belarus suffered the most, but atomic dust was drifted by the wind to many kilometers from the accident epicenter and fell far away from Ukraine.

The project's idea was born after several years of the accident. In the first year after the accident, a covering of the fourth power unit - sarcophagus - was built by Ukraine. It covered the destroyed unit and prevented the spread of jetting actions into the air. However, in course of time, the existing sarcophagus began to ruin and the creation of a new construction above the destroyed unit was suggested. This construction would ensure the environmental safety of the environment and would exist for many years.

4 chnpp.gov.ua (accessed 11 November 2017). 
At present, a lot of fuel exists in the nuclear power plant of the unit. The task of reconstruction of the Shelter Object was to build a new isolating arch construction covering the ruined unit to prevent jetting actions into the air and convert this unit into an ecologically safe system in terms of personal protection, radiological safety, and safe environment. ${ }^{4}$

\subsection{Interaction between mental spaces of the movable context and project manager}

According to the described steps in Section 3.1, the interaction was organized as follows:

1. The expert approach was used for the determination of the sets of the movable context that have the greatest impact on the project. All the sets of the movable context had an impact on the project.

2. The project manager had the opportunity to interact with all the sets.

2.1. The following subsets had the greatest impact:

2.1.1. the political influences of the global context, country context, economic sector, and organizational context;

2.1.2. the legal influences of the set of economic sector;

2.1.3. the infrastructure influences of the set of country context, economic sector, and organizational context;

2.1.4. the scientific and technical influences of all sets of the movable context; and

2.1.5. the natural and environmental influences of the country context.

2.2. According to clause 2.1.1, elements that had the greatest impact were as follows:

2.2.1. "Political support of the country in the world political arena" for the global context set: this interaction was presented through the close collaboration of Ukrainian project managers and the project managers of the international consortium who were included in the Project Management Unit. The methods used were negotiations, presentations, round tables. Information units were the project presentations, strategic development of the industry, and CNPP in the future, economic analysis, etc.

2.2.2. "Project support by the country's government" for the set of the country context: the government provided maximum support to the project NSCC at both the political level and the economy level. The methods used were presentations and meetings. Information units were the project reports.

2.2.3. "Project support for the industry" for the set of the economic context: such interaction was represented by providing continuous and comprehensive support at the organization level. Methods and information units were similar to the set of the country context (see clause 2.2.2);

2.2.4. "Project support by the organization's management" for the set of the organizational context: CNPP is an organization that is interested in quality and timely implementation of the project; its employees are directly involved in the project. For effective implementation of the project NSCC, CNPP financed learning project management for its staff during a few years to enhance their skills and provide new knowledge, skills, and practice for better implementation of the project. The methods used were meetings, organization and financial support for training, certification of employees in project management, and master classes. Information units were the information about the project approach, its benefits, and the need for use and study.

For clause 2.1.2, such an element was "Laws and legally enforceable enactments that are regulating activities within the industry" for the set of the economic sector. It happened through receiving separate written permission of the State Nuclear Regulatory Inspectorate of Ukraine to carry out work on the construction and installation of the first start-up facility of NSCC of the Shelter Object. The methods used were negotiations and meetings. Information units were the information about the state of the fourth block and its impact on the environment.

For clause 2.1.3, such elements were "communication industry," "communications," "mobile network coverage in the country," and "level of energy supplies in the country" for the set of the country context; "industry logistics" and "logistics" for the set of the economic sector; and "communication networks," "internal information 
systems," "communication," and "engineering support" for the set of the organization context. The interaction was provided through the provision of logistics and mobile communication, ensuring road service, and so on. The methods used were procurement procedures and negotiations. Information units were documentation on procurement and contract between contractors and those who provided services (e.g. mobile communication companies).

For clause 2.1.4, practically all elements of the subset of the scientific and technical influences of all sets of the movable context had the impact because the project product was technically complex and unique. A new, non-standard solution of the problem based on modern achievements in the research and technical fields was needed. The interaction was presented through involving advanced scientific achievements related to construction, nuclear power, nuclear physics, and so on. The methods used were round tables and seminars. Information units were justified approaches to solving the problem on the basis of the latest achievements in physics, mathematics, and engineering.

For clause 2.1.5, such elements were "temperature," "precipitation," "humidity," “winds," "landscape," "requirements for environmental protection," and "quality standards for water resources, soils, and air." The interaction was represented through usual control of ecology and natural condition of the Shelter Object and informing the public about the results of such monitoring. The method used was presentations. Information units were information messages and reports.

\subsection{Interaction between mental spaces of the project manager and stakeholders}

The interaction between mental spaces of stakeholders and the project manager happened through the blended mental space (Figure 2). The interaction can be considered according to the steps of Section 3.2.

1. The stakeholders were:

- the population of Ukraine;

- the population of surrounding countries;

- experts from CNPP;

- members of the international consortium, which included the company Bechtel (USA), Battelle (USA), and EDF (France);

- the EBRD; and

- contracting organizations involved in the construction works of building NSCC.
2. The contractor organizations were under direct influence of the project manager/project team. The project manager also had enough direct influence on the international consortium. The project manager had the mediated influence on the EBRD. The EBRD and the international consortium had the mutual influence.

3. Using the mutual influence between the EBRD and the international consortium, the project manager received an influence channel on the EBRD.

4. At the beginning of the project implementation, the stakeholders' influence was positive.

The consequences of the accident still had a strong negative impact on the population of both Ukraine and the surrounding countries (especially, the Republic of Belarus); hence, the closure and isolation of the fourth block were comprehensively supported by the population of Ukraine and surrounding countries.

The experience of mitigation of the man-made accident of such size in the nuclear power industry is unique and invaluable; hence, the international consortium had positive attitude. In addition, the expectation of gaining experience in disinfecting the territory from radioactive substances and the possibility of investigating the impact of the accident on the environment also contributed to a positive impact.

The EBRD had the positive impact because it agreed to finance the project. In the case, if the EBRD had only the negative or neutral impact, it would not have agreed to take part in the project financing or carried out it with the significant attraction of the state funds of Ukraine.

The experience of participating in the project is invaluable and unique also for contracting organizations. In addition, the successful implementation of the project ensures the improvement in the organization's portfolio.

Ensuring the safety of personnel at other CNPP units and eliminating foci of infection were the basis for the CNPP's positive impact.

The stakeholders' influence had changed during the project implementation. If the influence of the population of Ukraine and the surrounding countries did not change, then the other participant's influence changed. The movable context influenced on the changing of the influence of the EBRD and the international consortium. Their influence shifted from positive to negative. It was due to long terms of approving the necessary permits and the pace of project implementation. In such situations, CNPP experts organized round tables of the representatives of state bodies with the experts of the international consortium to work out solutions to existing problems. Such 
round tables were helping to find consensus and change the influence. They showed the interest of the movable context in the project implementation. In addition, the changing influence of the international consortium was helping to change the EBRD's influence.

The CNPP's influence also changed from positive to negative. It was together with getting close the project to complete. This was expressed in the creation of certain obstacles in the project implementation in order to delay the timing. This approach was conditioned by the emotional experience of CNPP employees for their future (employment) after the project will be completed. The CNPP management, having used the additional competence element "change and transformation" from the field "practice," developed and coordinated with the movable context (the executive government) and continued the existence of the CNPP as an ecological safety system. Tourism can be considered as one of the promising areas in the system.

The influence of contractor organizations had also changed. The interaction between the contracting organizations and project manager are given in more detail in the following.

Distribution of responsibilities and introduction of innovations were ways to solve the problem of changing the influence of contractor organizations.

The project team was responsible for solving problems of stability and imperviousness of existing structures of the Shelter Object and CNPP. The main contractor organization of NSCC makes provision lack loadings between the existing (the Shelter Object) and new (NSCC) designs for providing safety of the construction and prevention of the Shelter Object destroying. The main contractor should execute abutting of the old and new designs and provide caulking between them.

For the project, the interaction was organized also through innovation in implementation by both the project team and the contractor organization.

Innovations were presented by the project team in the form of temporary radioactive waste (hereinafter RAW) storage at a distance of $1 \mathrm{~km}$ from CNPP. This innovation gave the possibility to accelerate the land work inasmuch as provided quick release areas for the construction of NSCC from RAW. The possibility of the temporary storage was necessary because particularities of the project's works were the large amounts of RAW during land works' installation of building a base for NSCC, technological building, and building of ancillary structures. On 13 April 2014, all 104,000 m³ of RAWs were collected, conditioned, and shipped for disposal in the frame of the project NSCC. The burial site of RAWs
"Buryakovka" was the main place for RAW burials in the exclusion area. The distance from the State Specialized Enterprise CNPP to Buryakovka is $22.5 \mathrm{~km}$. To reduce the time, the project team completed subproject for temporary storage of RAW at a distance of $1 \mathrm{~km}$ from CNPP. All necessary approvals from regulatory agencies (including the Ministry of Health and the State Nuclear Regulatory Committee) had been received prior to the approval and implementation of the subproject. As a result, the time of land works was greatly accelerated.

The contractor organization's innovations were presented as proposals to carry out the installation of NSCC building's envelope, including arch barrel, western and eastern end walls, and crane facilities (cranes mounted on the supporting structures of the shell, garages, etc.) at a distance of $330 \mathrm{~m}$ from the location. This innovation made it possible to significantly reduce the dose rates of staff in the performance of work.

However, this proposal has set a difficult engineering task, in other words, the movement of the arch structure weighing 35,000 tons, a span of $257 \mathrm{~m}$, a height of $109 \mathrm{~m}$, and length of $162 \mathrm{~m}$. Partly, this problem has already been implemented: the movement of the eastern and western parts of the arch in the parking area has been done successfully.

The second proposal was to minimize dose rates. For the realization of the proposal, major work was carried out on the installation of arch at a height of $40 \mathrm{~m}$. However, this proposal, taking into account that the final height of construction was $109 \mathrm{~m}$, has set a new engineering problem, namely, the construction of lift on the arch at height. This task was achieved on 29 November 2016.

Another engineering problem was solved during the arch installation with the help of high-strength bolts called Tension Control Bolts (TCBs). The use of bolts allowed to transfer all the processes of welding designs in factory conditions, which greatly accelerated the pace and quality of the work. This project provided use of 650,000 TCBs.

The interaction between mental spaces of the project manager and contractor organization is presented in Figure 4.

\subsection{Interaction between mental spaces of stakeholders, the movable context, and the project manager}

The project manager was responsible for the organization of interaction between stakeholders and the movable context. It was organized through the adoption of the "Shelter Object Implementation Plan," which was 


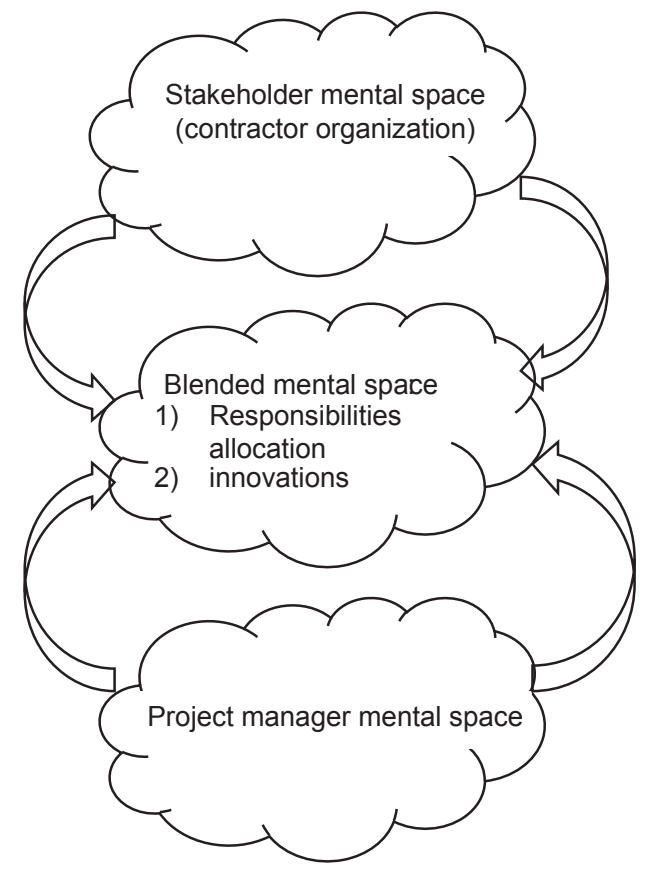

Fig. 4: Interaction between mental spaces of stakeholders (contractor organization) and the project manager.

developed by Ukraine and the international community in the frame of implementation of several additional previous projects. The result was an understanding that the current problem is complex and cannot be realized in one project. It needed to solve a number of issues, such as

- removal of the fuel-containing materials (hereinafter FCMs);

- handling of RAW;

- development of control systems for existing and new Shelter Object; and

- the rise of nuclear safety, etc.

The project NSCC is a good example of a long period of interaction between mental spaces of the movable context and stakeholders. Apart from the Shelter Object Implementation Plan, such interaction was provided via conduction of an international competition, in the frame of which was developed the stage-by-stage concept of Shelter Object transformation into an ecologically safe system. This competition was conducted by Ukraine in 1992. ${ }^{4}$ The concept became the basis for the development of technical and economic ground of the Shelter Object transformation into an ecologically safe system. The development of technical and economic ground was carried out in the framework of an international consortium. The technical and economic ground was the basis for a recommended course of action for the creation of the ecologically safe system. The potential short-term and long-term measures were identified in the recommended course of action, and a set of priority measures was proposed.

In addition, the interaction between mental spaces of the movable context and stakeholders was presented through creation of the special Chernobyl Shelter Fund. The fund administrator was the EBRD.

In this case, the stakeholders' mental space interacted with the movable context's mental space through the blended mental space that was created from the converted elements of these mental spaces (Figure 5). This interaction was embodied in the following information flows:

- informing the world community about the man-made accident;

- attracting international experts to study, predict, and assess accident's results;

- informing the international community about the status of the Shelter Object and creating interest to solve the Shelter Object's problem through the initiation of international projects concerning the study and providing of suggestions for solving the problem;

- involving Ukrainian specialists in the sphere of nuclear energy to solve problems;

- developing and signing of a series of international agreements that were determined to solve the problem of the fourth unit; and

- creating information space for the development and adoption of bylaws that would implement the project.

The agreed technical documents were the result of such cooperation.

\section{Future research}

In the author's opinion, further research in the field of the study of mental spaces will be interesting in both scientific and practical communities.

For scientists, the research in the organization and management by the effectiveness of interaction in the project implementation process should be interesting. Managing by the blended mental space is an understanding that one side understands and accepts what the other side is telling. In such a case, the approved project goals will be achieved. In addition, the problem of formalizing the interaction is interesting too. It can be conductive to its effectiveness. The interaction problem is a complex and ill-defined problem. Nevertheless, there are some approaches for the formalization of its aspects such as 


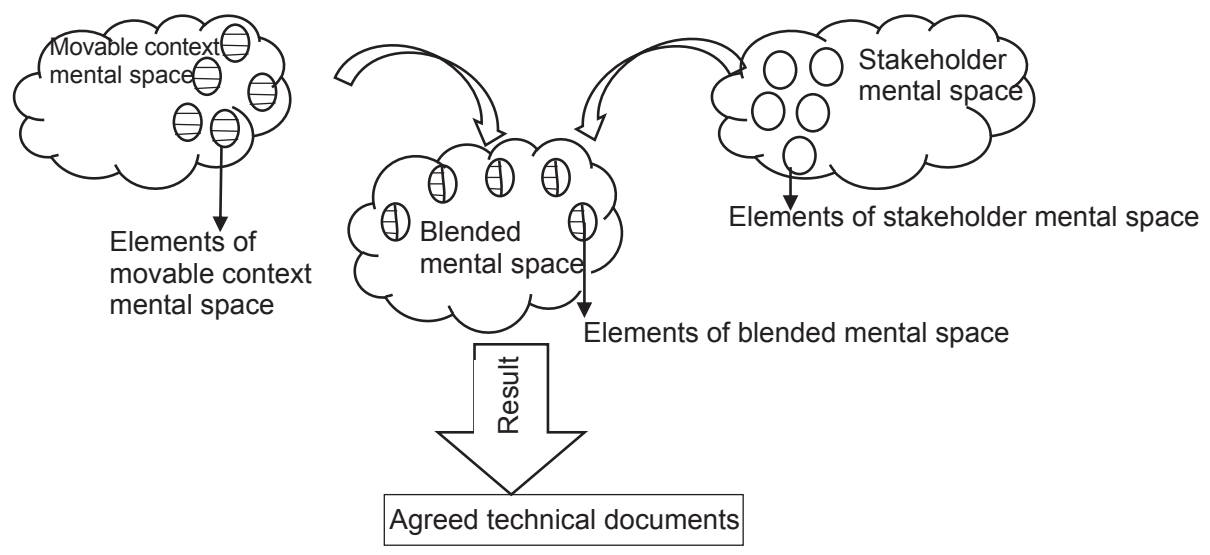

Fig. 5: Interaction between mental spaces of the movable context and stakeholders.

Verenych (2016c) and Dorosh et al. (2016). The formalized approaches provide more accurate and clear assessments and approaches, providing a basis for analysis and making management solutions. The focus of such research can be directed to:

- studying approaches for organizing the management of mental spaces;

- studying the influence of various factors on the interaction within the project through mental spaces;

- studying the possibilities of processes formalization of interaction with the use of information and communication technologies and higher mathematics.

For practitioners, in the author's opinion, the research results of the obtained application should be interested in the context of the implementation of the different projects, not only construction, and evaluation of achieving both greater efficiency and gains in the performance of the received application.

\section{Conclusions}

Organization of the interaction between the mobile context, stakeholders, and the project manager during development and implementation is an important action. The created blended mental space allows the project manager to manage the interaction through the temporary union of knowledge, practice, and skills in order to obtain a unique product of the project. The blended mental space transforms knowledge, practice, and skills in new knowledge, practice, and skills, which after the closing of the project enriches each mental space by extending and deepening its content. In fact, the blended mental space can be seen as the space for knowledge transformation from which knowledge should migrate to the knowledge bases.
The author considered step-by-step approaches for organizing interaction within the project through the blended mental space. These step-by-step approaches were demonstrated using the example of implementing the unique infrastructure project. Note that the approach is quite universal and can be applied for not only infrastructure projects but also a wide range of projects. The organization of interaction was carried out by the project manager and was based on the application of certain competence elements. The list of required competence elements was based on the International Project Management Association standard. The absence of such competence elements does not contribute to the organization of a fruitful and effective work within the project. One of the results of this research is also the development of a competency-based approach for determining the level of professional training of project managers.

\section{References}

Balashov, A. I., Rogova, E. M., Tikhonova, M. V., \& Tkachenko, M. V. (2013). Project Management: Text-book for Bachelor [Upravlenie proektami: uchebnik dlia bakalavrov]. Yurai, Moskow, Russia.

Bourne, L., \& Walker, D. H. T. (2006). Visualizing stakeholder influence - two Australian examples. Project Management Journal, 37(1), pp. 5-21.

Boychenko, G. N., Gurevich, L. I., \& Kundozerova, L. I. (2008). Organization culture of distributed education project in personality's mental space development. European Journal of Natural history, 2, pp. 90-92.

Burak, N., \& Rak, Yu. (2014). Model of project information environment of rescuers training improvement in mental space of IT technologies [Model proektno-informatsiinogo seredovyshcha pokrashchennia pidgotovky riatuvalnykiv v mentalnomu prostori IT-tekhnologii]. LDU BZHD Newsletter, 10, pp. 24-31.

Bushuev, S., Yaroshenko, R., \& Yaroshenko, N. (2011). Mental space formation of innovation development. Eastern-European 
Journal of Enterprise Technologies, 1/5(49), pp. 4-7. Available at: http://journals.uran.ua/eejet/article/view/1966/1861.

DeKarlo, D. (2005). eXtreme Project Management. Kompania p.m.Office, Moskow, Russia.

Dorosh, M., Trunova, O., Itchenko, D., Voitsekhovska, M., \& Dvoieglazova, M. (2016). The study of participants' values convergence on the example of an international scientific project on cyber security. Eastern-European Journal of Enterprise Technologies, 6/3(84), pp. 4-11. doi:10.15587/17294061.2016.85215.

El-Gohary, N. M., Osman, H., \& El-Diraby, T. E. (2006). Stakeholder management for public private partnerships. International Journal of Project Management, 24(7), pp. 595-604. doi:10.1016/j.ijproman.2006.07.009

Glebkin, V. (2013). Fauconnier's and Turner's Conceptual Blending Theory [Teoria conseptualnoy integrasii Fokone i Ternera]. Available at http://vphil.ru/index.php?option=com content\&task=view\&id=826 (accessed 18 November 2016).

Hoffman, Ed, \& Boyle, J. (eds.). (2015). R.E.A.L. Knowledge at NASA. A Knowledge Service Model for the Modern Project Environmental. Available at https://www.pmi.org/businesssolutions/white-papers/real-knowledge-nasa on 30 May, 2016.

IPMA Global Standards. (2015). Individual Competence Baseline for Project, Programme \& Portfolio Management, Version 4.0. International Project Management Association, 1, 432 p. ISBN (pdf): 978-94-92338-01-3; ISBN (print): 978-94-92338-00-6.

Kutsenko, M. (2011). Mental space formation and network knowledge creation in innovation programs development [Formirovanie mentalnogo prostranstva I sozdanie seteiy znaniiy v programmah innovatsionnogo razvitia]. Management of Development of Complex Systems, Issue 8, pp. 28-34.

Ludwig, E. (2009). All ears. PM Network, 23(3), pp. 56-63.

Mazur, I., Shapiro, V., \& Olderogge, N. (2004). Project Management [Upravlenie proektami]. Omega - L, Moskow, Russia.

Nonaka, I., \& Takeuchi, H. (1995). The Knowledge - Creating Company. How Japanese Companies Create the Dynamics of Innovation. Oxford University Press, New York, NY.
Reschke, H., \& Schelle, H. (eds.). (1990). GPM state-of-the-art book Dimensions of Project Management. Springer-Verlag, Germany.

Salikov, R.V. (2006). Comparison as a result of the interaction of the mental spaces [Sravnenie kak resultat vzaimodeistvia mentalnyh prostranstv]. Tombov university Newsletter. Issue: Human Science, 2, pp. 224-226.

Trincade, C. P., \& Ataide, C. G. (2013). Inter-organizational knowledge conversion and innovative capacity in cooperative networks. Journal of Technology Management \& Innovation, 8, pp. 17-18. doi: 10.4067/s0718-27242013000300009.

Turner, M., \& Fauconnier, G. (1995). Conceptual integration and formal expression. Journal of Metaphor and Symbolic Activity, 10(3), pp. 183-204.

Verenych, O. (2015a). Conceptual model of mental space formation [Konseptualna model' formuvannia mentalnogo prostory]. Management of Development of Complex Systems, Issue 23(1), pp. 39-43.

Verenych, O. (2015b). Formalized model of project manager/project team mental space. Management of Development of Complex Systems, Issue 24, pp. 23-29.

Verenych, O. (2016a). Development and implementation of formalized model of mental space of project or program environmental. Eastern-European journal of Enterprise Technologies, 2/4(80), pp. 21-31. doi:10.15587/1729-4061.2016.65635.

Verenych, O. (2016b). Formalized model of stakeholders mental space. Management of Development of Complex Systems, Issue 26, pp. 58-66.

Verenych, O. (2016c). Practical application of the analytic hierarchy process in project management. Management of Development of Complex Systems, Issue 27, pp. 36-43.

Whitty, S. J. (2005). A memetic paradigm of project management. International Journal of Project Management, 23(8), pp. 575-583. doi:10.1016/j.ijproman.2005.06.005.

Yaroshenko, F. A., Bushuev, S. D., \& Tanaka, H. (2012). Innovative Projects and Programs Management on the Base of A System of Knowledge P2M [Upravlenie innovatsionnymi proektami i programmami na osnove sistemy znaniy P2M]. Sammit-kniga, Kyiv, Ukraine. 